\title{
Selective suppression of CD44 in keratinocytes of mice bearing an antisense CD44 transgene driven by a tissue-specific promoter disrupts hyaluronate metabolism in the skin and impairs keratinocyte proliferation
}

\author{
Gürkan Kaya, Ivan Rodriguez, Jose L. Jorcano, ${ }^{1}$ Pierre Vassalli, and Ivan Stamenkovic ${ }^{2,3}$ \\ Department of Pathology, University Medical Center, University of Geneva, Geneva, Switzerland; ${ }^{1}$ Department of Cell and \\ Molecular Biology, Centro de Investigaciones Energeticas, Medioambientales y Tecnologicas (CIEMAT), 28040 Madrid, \\ Spain; ${ }^{2}$ Department of Pathology, Harvard Medical School, and Pathology Research, Massachusetts General Hospital, \\ Boston, Massachusetts 02129 USA
}

CD44 is a broadly distributed polymorphic glycoprotein that serves as the principal cell-surface receptor for hyaluronate. Although CD44-mediated cell interaction with hyaluronate has been implicated in a variety of physiologic events, including cell-cell and cell-substrate adhesion, cell migration, proliferation, and activation, as well as hyaluronate uptake and degradation, the biologic role of CD44 in vivo in various tissues remains to be determined. In the present work we have developed transgenic mice that express an antisense CD44 cDNA driven by the keratin-5 promoter. These mice lack detectable CD44 expression in skin keratinocytes and corneal epithelium and display abnormal hyaluronate accumulation in the superficial dermis and corneal stroma, distinct morphologic alterations of basal keratinocytes and cornea, and defective keratinocyte proliferation in response to mitogen and growth factors. These alterations are reflected by a decrease in skin elasticity, impaired local inflammatory response and tissue repair, delayed hair regrowth, and failure of the epidermis to undergo hyperplasia in response to carcinogen. Our observations indicate that two major functions of CD44 in skin are the regulation of keratinocyte proliferation in response to extracellular stimuli and the maintenance of local hyaluronate homeostasis.

[Key Words: CD44 glycoprotein; hyaluronate disruption; transgenic mice; keratinocyte proliferation]

Received December 20, 1996; revised version accepted March 12, 1997.

CD44 is a polymorphic integral membrane glycoprotein whose diversity is determined by variable exon usage, glycosaminoglycan substitution, and cell type-specific $\mathrm{N}$ - and O-linked glycosylation /Stamenkovic et al. 1991; Screaton et al. 1992; Lesley et al. 1993; Bennett et al. 1995). Thus, CD44 proteins range from $90 \mathrm{kD}$ for the standard isoform, which contains no variant exon products-usually referred to as $\mathrm{CD} 44 \mathrm{H}$ - to $>250 \mathrm{kD}$ for isoforms containing all of the variant exon products and high molecular weight glycosaminoglycans. $\mathrm{CD} 44 \mathrm{H}$ is the isoform expressed most broadly, and is found on both mesenchymal and epithelial cells. Variant exon-containing CD44 isoforms have a more restricted expression pattern and are found chiefly in cells of epithelial origin (Stamenkovic et al. 1991).

${ }^{3}$ Corresponding author.

E-MAIL stamenkovic@helix.mgh.harvard.edu; FAX (617) 726-5684.
Although CD44 has been proposed to bind multiple ligands, including collagens, fibronectin (Jalkanen and Jalkanen 1992), chondroitin sulfate (Naujokas et al. 1993), osteopontin (Weber et al. 1996), and at least two heparinbinding growth factors (Bennett et al. 1995), it is currently thought to be the principal cell-surface receptor for hyaluronate [(HA) Aruffo et al. 1990; Miyake et al. $1990 \mathrm{~b}]$. HA is a ubiquitously distributed, negatively charged high molecular weight polysaccharide composed of glucuronic acid and $N$-acetylglucosamine disaccharide repeats (Fraser and Laurent 1989; Laurent and Fraser 1992). The HA polymer can adopt a coil structure in solution that becomes a highly hydrated sphere capable of accommodating several orders of magnitude more water than polymer (Laurent and Fraser 1992). HA may therefore help create a hydrated, low-resistance matrix that facilitates cell trafficking. However, together with several proteoglycans and HA-binding proteins, HA also 
plays an important role in organizing the extracellular matrix (ECM) structure. HA production is enhanced in situations associated with cell proliferation, including limb development, tissue remodeling, inflammation, and tumor invasion (Toole 1982), and recent evidence indicates that HA may have a significant part in modulating cell proliferation, migration and activation in vitro and in vivo (Toole 1982, 1990).

CD44 has been implicated in cell-cell adhesion and cell attachment to ECM (Lesley et al. 1993), cell migration (Thomas et al. 1992), tissue remodeling, lymphocyte recirculation, and homing (Jalkanen et al. 1986), hematopoiesis (Miyake et al. 1990a), lymphocyte activation (Shimizu et al. 1989), and tumor growth and metastasis (Gunthert et al. 1991; Sy et al. 1991; Bartolazzi et al. 1994). Most of these functions can be attributed, at least in part, to CD44-HA interaction. In addition, several lines of evidence indicate that CD44 can mediate HA uptake and degradation (Culty et al. 1992). However, despite abundant evidence of its involvement in multiple physiologic and pathologic processes, the main biologic roles of CD44 in specific tissues where it is permanently expressed remain to be elucidated.

Basal keratinocytes of the skin display a high level of CD44 expression. This raises questions as to the role of CD44 in skin tissular organization and in a variety of skin processes associated with HA production and potentially involving CD44-HA interaction, such as wound healing, tissue remodeling, and inflammation. To address the physiologic role of CD44 in this location, we developed transgenic mice with a keratinocyte-specific CD44 expression defect. Our results show that CD44 borne by keratinocytes plays a major role in the regulation of keratinocyte proliferation and local HA metabolism.

\section{Results}

\section{Development of K5-CD44-antisense transgenic mice}

The DNA construct used to generate the transgenic mice is shown in Figure 1A. The 5.2-kb fragment of the $5^{\prime}$ regulatory region of the bovine keratin-5 (K5) gene used to promote expression of the antisense CD44 cDNA has been shown to target the expression of reporter genes to the basal cell compartment of stratified squamous epithelia and the outer root sheath (ORS) of hair follicles (Ramirez et al. 1994). Southern blot analysis of tail-derived DNA identified five founder mice each harboring between a few to up to 40 copies of the transgene (Fig. 1B). Expression of the transgene, as detected by RT-PCR using antisense CD44 sequence-specific oligonucleotide primers, was observed in the five founder mice (Fig. 1C). Immunofluorescence microscopy of dorsal skin sections from two of these mice (lines 3 and 10), using an antiCD44 antibody that recognizes epitopes common to all isoforms, revealed complete loss of CD44 expression in all layers of the epidermis and the ORS of hair follicles. Suppression of CD44 expression was confirmed by im-

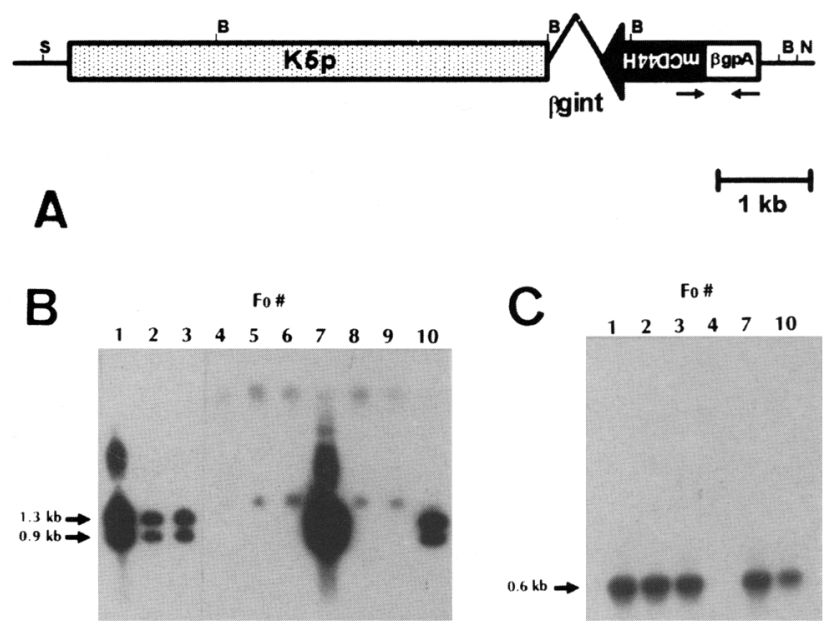

Figure 1. The K5-CD44AS transgene construct, identification of transgenic mice, and analysis of transgene expression. $|A|$ Schematic representation of the K5-CD44AS transgene construct. In an antisense orientation $1.1 \mathrm{~kb}$ of the entire murine $\mathrm{CD} 44 \mathrm{H}$ ( $\mathrm{mCD} 44 \mathrm{H}$ ) cDNA (solid box) was cloned downstream of the $5.2-\mathrm{kb}$ bovine keratin 5 promoter (K5p) (stippled box) between the rabbit $\beta$-globin intron ( $\beta$ gint) (connecting line) and the polyadenylation site ( $\beta g p A)$ (open box). Short arrows indicate primers used to determine antisense RNA expression. (S) SalI; (B) BamHI; (N) NotI. (B) Southern blot analysis of BamHldigested mouse tail DNAs (10 $\mu \mathrm{g}$ each) from founder $\left(\mathrm{F}_{0}\right)$ mice. The blot was hybridized with radiolabeled entire $\mathrm{mCD} 44 \mathrm{H}$ cDNA. Expected bands were 0.9 and $1.3 \mathrm{~kb} .(\mathrm{C})$ Antisense CD44 RNA expression in $F_{0}$ transgenic mice. Reverse-transcribed total RNA from dorsal skin of mice was subjected to PCR using antisense CD44 and polyadenylation sequence-specific oligonucleotides, followed by Southern blot analysis with radiolabeled $\mathrm{mCD} 44 \mathrm{H}$ cDNA. The expected message was $0.6 \mathrm{~kb}$. munofluorescence and Western blot analysis of cultured transgenic mouse-derived keratinocytes and corresponding lysates (data not shown). In contrast, increased CD44 expression was observed in the superficial dermis (Fig. 2), consistent with an increase in the number of local fibroblasts (see below). Almost all of the observations reported below are derived from the progeny of founder no. 3 ; double transgenic mice resulting from the crossing of lines 3 and 10 had the same phenotype as mice having a single transgenic construct.

Of $36 \mathrm{~F}_{1}$ progeny obtained by crossing the two transgenic founders with C57BL/ 6 mice, 24 revealed the presence of the transgene as detected by Southern blot analysis. Newborn transgenic mice displayed no gross skin anomaly. Development of the first coat and progression of the second and third hair cycles proceeded with no notable difference with respect to control littermates. However, adult mice from each transgenic line displayed abnormally abundant hair loss following fights with other male littermates (data not shown). Hair regrowth in the transgenic animals required months compared to 2 weeks in nontransgenic littermates. 

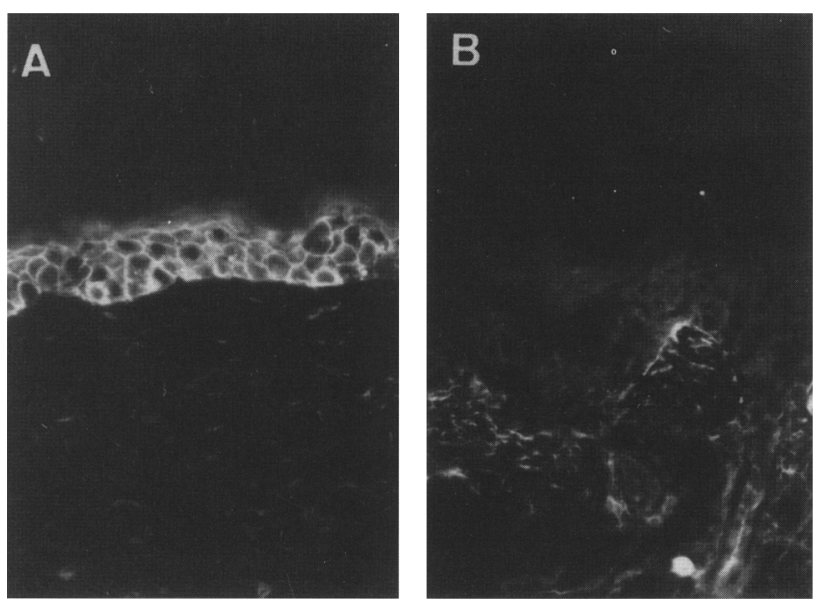

Figure 2. Immunohistological analysis of CD44 expression in transgenic skin. Frozen serial skin sections of control littermate $(A)$ and transgenic $(B)$ mice were stained with anti-mouse CD44 followed by fluorescein-conjugated goat anti-rat immunoglobulin antibody. Epidermis of control littermate shows intense immunoreactivity $\{A\}$, whereas CD44 staining is lost in transgenic epidermis $(B)$. Note the increased CD44 staining in the superficial dermis of the transgenic mouse. Original magnification, $40 \times$.

Loss of keratinocyte CD44 expression is associated with structural epidermal and dermal alterations

Histologic examination of skin sections from $>20$ adult transgenic mice showed characteristic changes in the basal layer of the epidermis, where cells had adopted an elongated rather than their characteristic round shape, and in the superficial dermis, mainly at the dermoepidermal junction, where an accumulation of loose connective tissue replacing the denser collagen layer, with the occasional appearance of small empty-looking vacuoles, was observed (Figure 3A,B,G,H). The dermal changes were most conspicuous in sections stained with van Gieson-elastin (Fig. 3C,D). Ultrastructural analysis showed that the desmosomes and hemidesmosomes, as well as keratinocyte differentiation, were normal. Although the epidermal basement membrane thickness and appearance were unaltered, electron microscopy underscored the severity of collagen fiber disorganization in the dermis and revealed accumulation of large vacuoles or the presence of lacunar regions beneath the basement membrane (Fig. 3I,J,K). In addition, superficial dermis fibroblasts displayed an abnormal phenotype, characterized by enlarged and convoluted nuclei, a markedly developed endoplasmic reticulum, frequently displaying striking dilatation or accompanied by empty-looking vacuoles, and elongated cytoplasmic processes (Fig. $3 \mathrm{~L}, \mathrm{M})$. The structure of the deeper layers of the dermis appeared normal. Large anagen-type follicles were prominent in transgenic animals (Fig. 3F,O), but follicles in other phases of the hair cycle were visible as well, indicating that loss of CD44 expression in follicular keratinocytes did not block the hair cycle in any given phase. There was no obvious relationship between the severity of the dermal/epidermal alterations, the sex of the mice, and the region of the skin examined (back, ear, or taill. However, the observed phenotype was age dependent. No histologic changes were detected in newborn mice. The first basal layer keratinocyte alterations appeared at 3 weeks, and the full spectrum of morphologic changes developed 6 weeks after birth. The described phenotype progressed with maturation and was most striking in animals $>18$ months of age.

Loss of keratinocyte CD44 expression is accompanied by accumulation of HA in the superficial dermis and beneath the corneal epithelium

In an attempt to identify the loose connective tissuetype material observed to accumulate in the superficial dermis, we employed mouse CD44-immunoglobulin fusion protein (mCD44Rg), which has proved to be a reagent of choice for localizing $\mathrm{HA}$ in tissue sections (Aruffo et al. 1990; Fenderson et al. 1993; Bartolazzi et al. 1994). Immunohistochemical analysis showed marked binding of mCD44Rg to the superficial dermis beneath the dermoepidermal junction in skin sections from transgenic but not from normal mice (Fig. 4A,B). Pretreatment of transgenic mice skin sections with hyaluronidase abrogated $\mathrm{mCD} 44 \mathrm{Rg}$ binding to the superficial dermis, indicating that the accumulated material is indeed HA (Fig. 4C).

Because the $\mathrm{K} 5$ promoter is active in the corneal epithelium (Byrne and Fuchs 1993), corneal tissue sections from transgenic and control mice were analyzed by histology and assessed for CD44 expression. Similar to the skin, cornea from transgenic mice did not express CD44 on corneal cells, in contrast to control cornea (data not shown), and displayed the same type of structural alterations, most notably the accumulation of loose connective tissue in place of the dense connective tissue normally found beneath the corneal epithelium (Fig. 5). The loose connective tissue bound CD44Rg (Fig. 5), and binding was abrogated by tissue section treatment with hyaluronidase (data not shown).

\section{Keratinocytes in $\mathrm{K} 5$-CD44-antisense transgenic mice display a defect in HA uptake}

Immunohistochemical analysis of normal mouse skin using $\mathrm{mCD} 44 \mathrm{Rg}$ showed hyaluronidase-sensitive punctiform inter- and intracellular epidermal staining, consistent with cell-surface binding and internalization of $\mathrm{HA}$ by keratinocytes. In contrast, $\mathrm{mCD} 44 \mathrm{Rg}$ failed to bind to the epidermis of transgenic mice (Fig. 4A,B). Because CD44 has been shown to be involved in the uptake and degradation of HA in various cell types (Culty et al. 1992), this observation is consistent with the possibility that the absence of CD44 may result in defective HA uptake by keratinocytes. We therefore cultured keratinocytes from dorsal skin of control and transgenic mice in the presence of fluorescein-tagged HA (HA-FL) for 1 or $24 \mathrm{hr}$. Confocal microscopy revealed cell-surface binding 

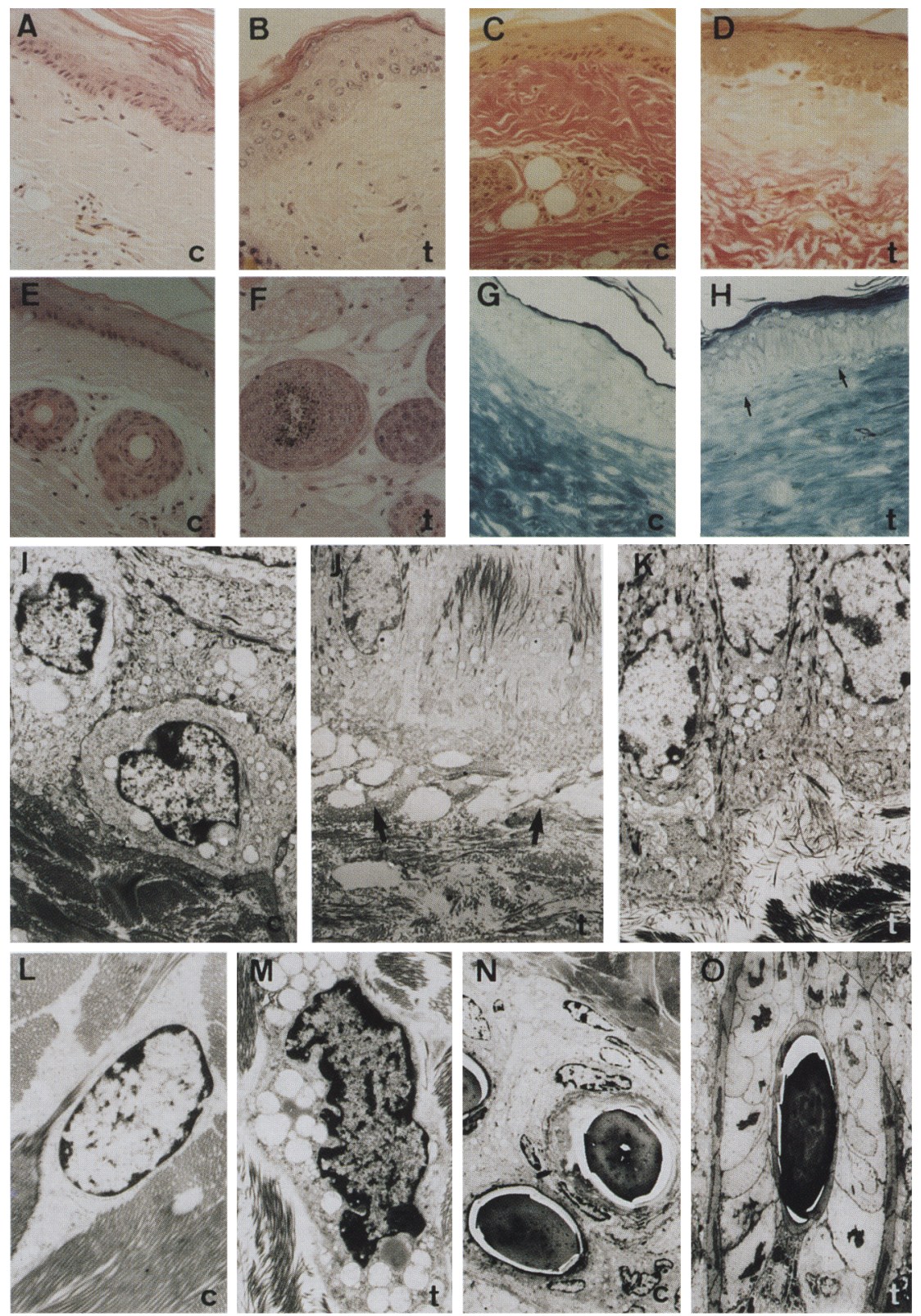
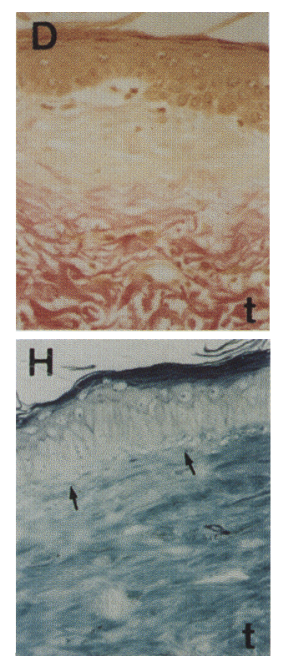

Figure 3. Histological and ultrastructural analysis of $\mathrm{K} 5-\mathrm{CD} 44$-antisense transgenic mouse skin. Tissue sections of control littermate (c) $(A, C, E, G)$ and transgenic $(\mathrm{t})$ $(B, D, F, H)$ mice stained with hematoxylineosin $(A, B, E, F)$ and van Gieson-elastin $(C, D)$. Shown are hair follicles of control $(E)$ and transgenic $(F)$ mice; methylene blue-stained semithin skin sections from control littermate $(G)$ and transgenic $(H)$ mice; ultrastructure of control littermate dermoepidermal junction $(I)$, dermal fibroblast $\{L\}$, and hair follicles $(N)$ and transgenic mouse counterparts $(J, K, M, O)$. Note the elongated appearance of keratinocytes $(B, H, K)$, disorganization and disruption of collagen bundles $(B, D, I, K)$, accumulation of loose connective tissue in the superficial dermis $(D, J, K)$, vacuoles beneath the basement membrane (arrows in $H$ and $J$, dissociation of the basement membrane from the underlying collagen bundles $(K)$, abnormal fibroblasts with enlarged endoplasmic reticulum and vacuolization $(M)$, and large anagen-type follicles $(F, O)$ in transgenic animals. Original magnification $40 \times(A-H) ; 2800 \times(I-O)$. of HA-FL at $1 \mathrm{hr}$ and internalization at $24 \mathrm{hr}$ by normal but not by CD44-negative transgenic keratinocytes (Fig. 6).

Keratinocytes not only bind and degrade HA but are also a site of HA synthesis. To determine whether loss of CD44 expression might affect HA synthesis by keratinocytes, we incubated primary keratinocyte cultures from transgenic animals and normal littermates with $\left[{ }^{3} \mathrm{H}\right]$ glucosamine and compared the amount of radiolabel incorporated into HA released into the supernatants and retained in membrane extracts (Culty et al. 1992; Underhill et al. 1993). Supernatants from transgenic and normal keratinocytes contained comparable radiolabeled HA $\left(175 \pm 17 \times 10^{3}\right.$ and $162 \pm 26 \times 10^{3}$ cpm, respectively). However, the membrane fraction of the trans- genic keratinocytes displayed significantly lower ${ }^{3} \mathrm{H}$-labeled HA than that of their normal counterparts $\left(9.5 \pm 3.9 \times 10^{3}\right.$ and $38.1 \pm 7.6 \times 10^{3} \mathrm{cpm}$, respectively), consistent with decreased HA binding. Fibroblasts from the superficial dermis of normal and transgenic mice showed comparable HA synthesis as assessed by $\left[{ }^{3} \mathrm{H}\right] \mathrm{glu}-$ cosamine incorporation (data not shown).

K5-CD44-antisense transgenic mice display abnormal skin elasticity, wound healing, and reaction to TPA

Handling of transgenic mice showed decreased skin elasticity in comparison to control littermates. This was substantiated by the observation that a simple dorsal incision conserved its linearity in control animals but im- 

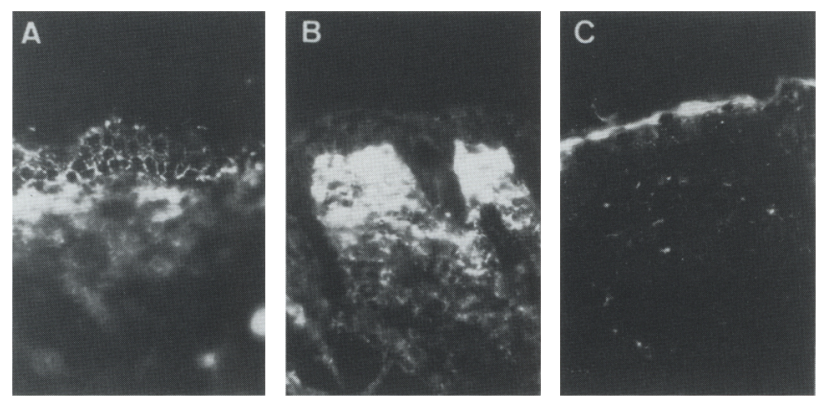

Figure 4. $\mathrm{mCD} 44 \mathrm{Rg}$ reactivity with transgenic mouse skin sections. Fluorescence micrographs of sections of control littermate $(A)$ and transgenic $(B, C)$ mice stained with $20 \mu \mathrm{g} / \mathrm{ml}$ mCD44Rg followed by fluorescein-conjugated goat anti-human IgG antibodies either without $(A, B)$ or with $|C|$ pretreatment of the section with $1 \mu \mathrm{g} / \mathrm{ml}$ of bovine testicular hyaluronidase. The interkeratinocyte staining pattern of mCD44Rg in control littermate epidermis $(A)$ is absent in transgenic mouse skin $(B)$. The strong reactivity of the transgenic mouse superficial dermis with $\mathrm{mCD} 44 \mathrm{Rg}(B)$ is abolished following treatment of the section with hyaluronidase $(C)$. The residual staining is attributable to autofluorescence of the corneal layer. Original magnification, $40 \times$.

mediately adopted a round shape in transgenic littermates (Figure $7 \mathrm{~A}, \mathrm{~B}$ ). Intradermal hyaluronidase injection into the transgenic animals $2 \mathrm{hr}$ prior to the incision restored elasticity, as assessed by the conservation of incision linearity, indicating that the reduction in skin elasticity in transgenic mice is related to HA accumulation in the superficial dermis (Fig. 7C). Intradermal injection of saline buffer, used as a control, failed to restore normal skin elasticity (data not shown).

The effect of keratinocyte CD44 expression loss on tissue repair was addressed by comparing the kinetics and histology of wound healing in transgenic and normal littermates. Single $1-\mathrm{cm}^{2}$ full-thickness dorsal wounds in control mice underwent complete reepithelialization within 12-14 days. In contrast, wound healing was delayed by 4-7 days in transgenic animals (Fig. 7D). In control mice, re-epithelialization was preceded by contraction of wound margins, formation of a scab, reduction of the wound surface, and loss of the scab upon resolution of the healing process. In the transgenic mice, contraction of the wound margin did not proceed normally and a rough yellowish scab persisted for 4-7 days following complete healing of the wounds in control mice (Fig. $7 \mathrm{E}, \mathrm{F} \mid$. Examination of wound sections $1,3,5$, and 7 days following full thickness incision revealed that all of the stages of wound healing, including leukocyte infiltration, granulation tissue formation, fibrosis, and re-epithelialization, were present in the transgenic mice (data not shown). Re-epithelialization appeared to be the single most delayed event. Repeated incisions in the same wound area of transgenic mice further accentuated the delay in tissue repair with respect to normal littermates (data not shown).

To address the possible effect of CD44 expression loss on keratinocyte proliferation, we performed a bromodeoxyuridine (BrdU) incorporation assay. BrdU was injected into animals in which $0.5-\mathrm{cm}^{2}$ wounds had been established, and the injured tissue stained with an antiBrdU antibody $2 \mathrm{hr}$ following injection. In control mice 5 days after injury, a large number of keratinocytes at the wound margin incorporated BrdU, whereas the number of BrdU-incorporating cells in the epidermis at the wound margin of transgenic mice was severalfold lower (Figs. 7, G and $\mathrm{H}$, and 8E). Impaired proliferation appeared to be restricted to keratinocytes, as the BrdU incorporation by cells in the underlying granulation tissue was similar in transgenic and control mice at this stage of wound healing.

We further analyzed keratinocyte proliferation in vivo in response to local application of tetradecanoylphorbol acetate [(TPA) Akhurst et al. 1988] to ear skin. Stimulation by TPA caused skin thickening in control mice within $48 \mathrm{hr}$ but induced no change in the skin of transgenic littermates. Histologically, the epidermis of the control mice displayed a characteristic increase in keratinocyte stratification, whereas epidermal thickening in transgenic mice was minimal (Fig. 8A,B). Although $35 \%-40 \%$ of keratinocytes in the epidermis of control mice incorporated BrdU $48 \mathrm{hr}$ after TPA application, only a few cells were positive in the transgenic mouse epidermis (Fig. 8C). It should be noted that stimulation of the skin with TPA induced increased expression of CD44 on proliferating keratinocytes in the control mice, which was completely absent in the transgenic animals (data not shown). Finally, 2 days after TPA application, the dermis of control mice showed a marked infiltration by polymorphonuclear cells, which was absent in transgenic mice, suggesting an impaired capacity of their altered skin to mount an acute inflammatory response.
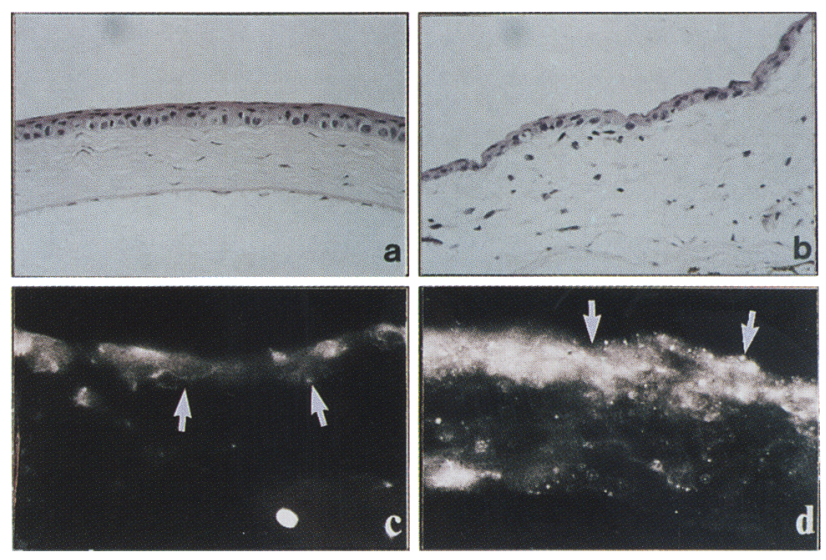

Figure 5. Corneal abnormalities in transgenic mice. Light $(A, B)$ and fluorescence $(C, D)$ microscopy of corneal sections from normal $(A, C)$ and transgenic $(B, D)$ mice. Note the accumulation of loose connective tissue beneath the corneal epithelium in transgenic mice $(B)$ and its strong reactivity with mCD44Rg $(D)$. The dermoepidermal junction in $C$ and $D$ is indicated by arrows. Original magnification, $40 \times$. 

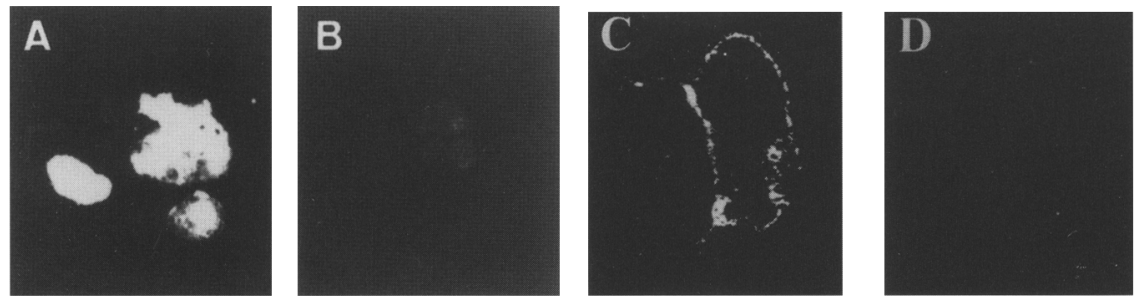

Figure 6. Uptake of HA-FL by transgenic keratinocytes. Epidermal keratinocytes of control littermate $(A, C)$ and transgenic $(B, D)$ mice were incubated with $100 \mu \mathrm{g} / \mathrm{ml}$ of HA-FL for $24 \mathrm{hr}(A, B)$ or $1 \mathrm{hr}(C, D)$ and examined under a confocal microscope. At $1 \mathrm{hr}$, normal but not transgenic keratinocytes display cell surface-bound HA-FL. After $24 \mathrm{hr}$, the HA is present inside normal but not transgenic keratinocytes. Original magnification, $1890 \times$.

Hair regrowth is delayed in K5-CD44-antisense transgenic mice

We compared hair regrowth in control and transgenic mice after pulling out the dorsal hair of the animals following the second hair cycle. In control mice, hair regrew normally within 10 days, whereas in transgenic mice hair regrowth was delayed for at least 5 days. Hair follicle keratinocyte proliferation was assessed by BrdU labeling 2 days after plucking. In control mice $39 \%( \pm 4)$ of follicular keratinocytes in the depilated area incorporated $\mathrm{BrdU}$, whereas in transgenic mice only $6 \%( \pm 2)$ of the corresponding follicular keratinocytes were BrdU positive (data not shown). Histologic examination of hair follicles at a series of time points following birth, which, in normal mice, correspond to different phases of the hair cycle (Andreasen 1953; Cotsarelis et al. 1990), revealed that the transgenic mice display all of the normal follicular phenotypes (data not shown), indicating that loss of CD44 expression does not result in any obvious disruption of the hair cycle.

\section{Carcinogen application fails to induce epidermal hyperplasia in transgenic mice}

To further address the effect of CD44 expression loss on the epidermal response to inducers of proliferation, the carcinogenic hydrocarbon 7,12-dimethylbenz [a]anthracene [(DMBA) Andreasen and Borum 1958] in benzene was applied to the dorsal skin of control and transgenic mice that were in the resting phase of their hair cycle. Twenty days following DMBA treatment, all of the control animals displayed severe ulcerative lesions with exsudation and hair loss at the site of DMBA application in contrast to transgenic mice, which revealed only minor lesions. The ulcerations persisted for at least 40 days in normal mice while the minor lesions visible in transgenic counterparts disappeared within 15 days. Histologic examination of the skin on day 60 following DMBA application revealed chronic ulceration with moderate to severe lymphocyte and granulocyte infiltration in normal mice (data not shown). The epidermis at the margin of the ulcer displayed marked hyperplasia with enlarged hair follicles (Fig. 9A). In contrast, the epidermis of transgenic mice failed to display ulcerative or hyperplastic changes (Fig. 9B).

Defective in vitro proliferation of K5-CD44-antisense transgenic mouse keratinocytes in response to injury, mitogen, and growth factors

To determine whether the observed lack of proliferation in response to injury, TPA, and possibly carcinogen is associated with HA accumulation in the superficial dermis or reflects a primary defect, cultured transgenic and normal littermate keratinocytes were tested for response to $1 \mathrm{ng} / \mathrm{ml}$ of TPA and $0.5-5 \mathrm{mg} / \mathrm{ml}$ of HA. Exposure to TPA resulted in increased proliferation of normal keratinocytes but failed to stimulate transgenic counterparts (Fig. 10A). Incubation with low concentrations of HA resulted in a slight but significant increase in normal keratinocyte proliferation but again failed to stimulate transgenic cells (Fig. 10A). Because keratinocytes normally express several CD44 isoforms, including exon v3containing variants, which are substituted in heparan sulfate side chains and bind basic fibroblast growth factor (bFGF) and heparin-binding epidermal growth factor [(HB-EGF) Bennett et al. 1995], we compared the ability of transgenic and normal littermate keratinocytes to proliferate in response to bFGF and HB-EGF. Amphiregulin (AR), which fails to bind CD44v3 (Bennett et al. 1995), was used as a negative control. Normal keratinocytes displayed increased proliferation in response to $0.5 \mathrm{ng} /$ $\mathrm{ml}$ of bFGF and $5 \mathrm{ng} / \mathrm{ml}$ of HB-EGF, whereas transgenic keratinocytes failed to show proliferative response. Neither cell type proliferated in response to AR at the concentration used (Fig. 10B).

\section{Discussion}

Previous work by others has demonstrated the feasibility of suppressing gene expression using an antisense cDNA expression strategy (Katsuki et al. 1988; Pepin et al. 1992). In the present work we have achieved tissue-selective suppression of $\mathrm{CD} 44$ expression by introducing the mouse CD44 cDNA in antisense orientation under the control of the keratinocyte-specific K5 promoter (Ramirez et al. 1994). Because the K5 promoter has also been used to overexpress an antisense $b c l 2$ transgene in the keratinocytes of transgenic mice which, despite expression of the transgene, failed to produce any detectable phenotypic alteration (I. Rodriguez and P. Vassalli, unpubl.), the effects of K5-CD44AS vector expression 


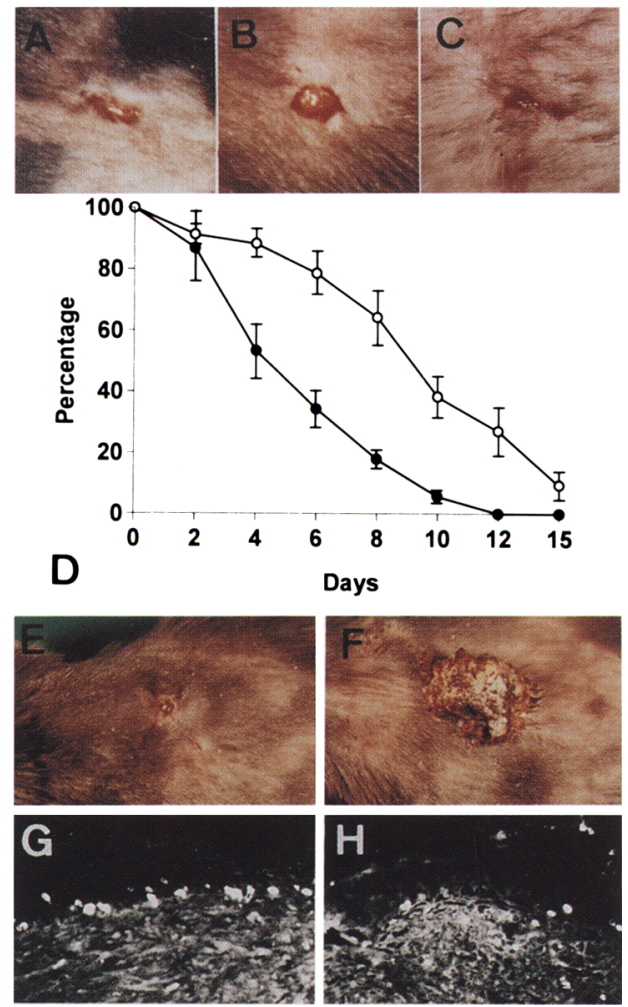

Figure 7. Analysis of wound healing in transgenic mice. Single full-thickness incisions $(A-C)$ or $1(D-F)$ or $0.5\{G, H\rangle \mathrm{cm}^{2}$ square-shaped wounds were made on the back of control littermate $(A, E, G)$ and transgenic $(B, C, F, H)$ mice as described in Materials and Methods. The linear shape of the incision in the control littermate $(A)$ is not conserved in the transgenic mouse, and incision immediately becomes round-shaped $(B)$, consistent with abnormal skin elasticity. Intradermal injection of bovine testicular hyaluronidase $2 \mathrm{hr}$ prior to the incisions restores the incision shape in the transgenic mouse $(C)$. Healing of $1-\mathrm{cm}^{2}$ square-shaped wounds is delayed in transgenic mice $(D)$. The data represent mean values from five transgenic mice $(O)$ and five control littermates (0). Data were grouped by measuring the wound surface areas every 2 days after wounding by planimetry until complete healing was reached in the control mice. The surface area of the wound expressed as a percentage of the wound surface area at day 0 was calculated for each animal. Square shaped wounds $\left(1 \mathrm{~cm}^{2}\right)$ were reepithelialized almost completely after 12 days in the control mice $\langle E\rangle$, whereas in the transgenic mice an abnormal scab was observed after the same period of time $(F)$, which persisted for another 4-7 days. Shown is BrdU labeling of keratinocytes at the wound margin of control $(G)$ and trangenic $(H)$ mice. A single full-thickness $0.5-\mathrm{cm}^{2}$ wound was made on the back of control and transgenic mice. On day 5 following injury, mice were injected with BrdU $(250$ $\mathrm{mg} / \mathrm{kg}$ ) and $2 \mathrm{hr}$ later wound tissue was isolated and processed for sectioning. Mid-wound sections were stained with a fluorescein-conjugated anti-BrdU antibody. Original magnification, $20 \times$.

reported here are unlikely to represent the nonspecific consequence of excessive K5 promoter usage but, rather, reflect the loss of cell-surface CD44. Abrogation of keratinocyte CD44 expression in mice was observed to have at least two major consequences: (1) the loss of $\mathrm{HA}$ in the interkeratinocyte spaces accompanied by abnormal accumulation of HA in the superficial dermis, and (2) the inhibition of keratinocyte proliferation in response to a variety of extracellular stimuli. These changes were associated with defects in skin elasticity, tissue repair, hair regrowth, and local inflammatory response and with lack of induction of epidermal hyperplasia following exposure to carcinogen, all of which may be interpreted as resulting from the two basic consequences of the loss of CD44 expression.

Keratinocytes and fibroblasts provide the principal source of HA in the epidermis and dermis, respectively. There is evidence that fibroblasts are also capable of internalizing HA, which leads to its subsequent degradation, and that this phenomenon is CD44-mediated (Bertolami et al. 1992). In this study we have shown that keratinocytes that are unable to express CD44 are also unable to bind and internalize HA in vitro, whereas their capacity to synthesize HA is unimpaired. It thus appears that CD44 expressed in keratinocytes and fibroblasts may play a major role in HA turnover in the skin, as shown by the absence of HA in the interkeratinocyte spaces of the transgenic mice, contrasting with its presence at this location in normal animals (Tammi et al. 1988, 1991; Wang et al. 1992; G. Kaya et al., this work). Because normal and transgenic fibroblasts showed comparable HA synthesis in vitro, HA accumulation is not likely to result from overproduction by local fibroblasts

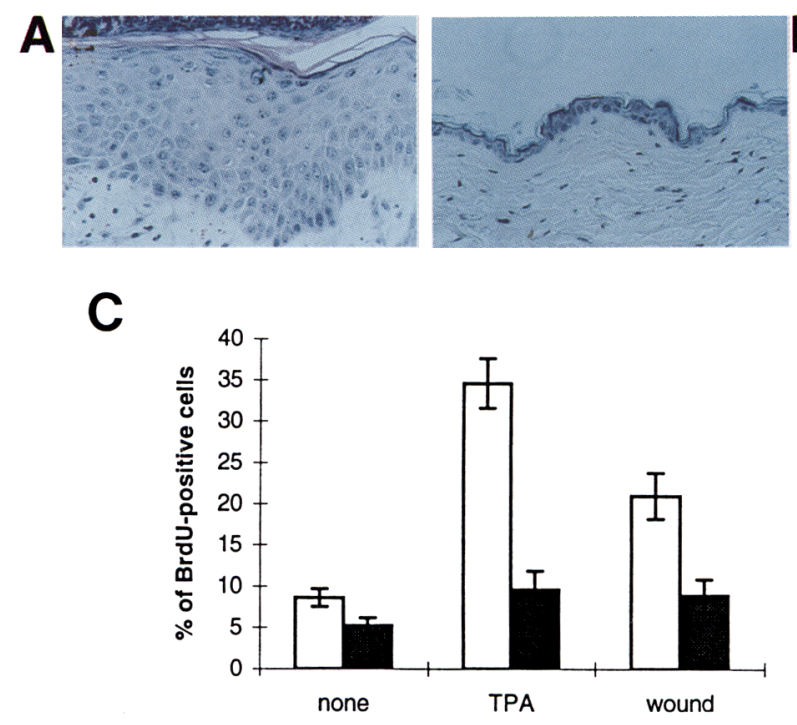

Figure 8. Analysis of keratinocyte proliferation in vivo after TPA application. TPA $\left(10^{-4} \mathrm{M}\right)$ was applied to each side of the ear of control and transgenic mice. Two days after TPA application, control mice displayed thickened epidermis with marked edema and a cellular infiltrate $(A)$, whereas transgenic mouse epidermis revealed virtually no thickening $(B)$. (C) Quantification of BrdU-positive cells in sections 2 days after TPA application to transgenic mice (solid bars) and controls (open bars); positive cells were scored in five microscopic fields in each section. Original magnification, $40 \times$. 

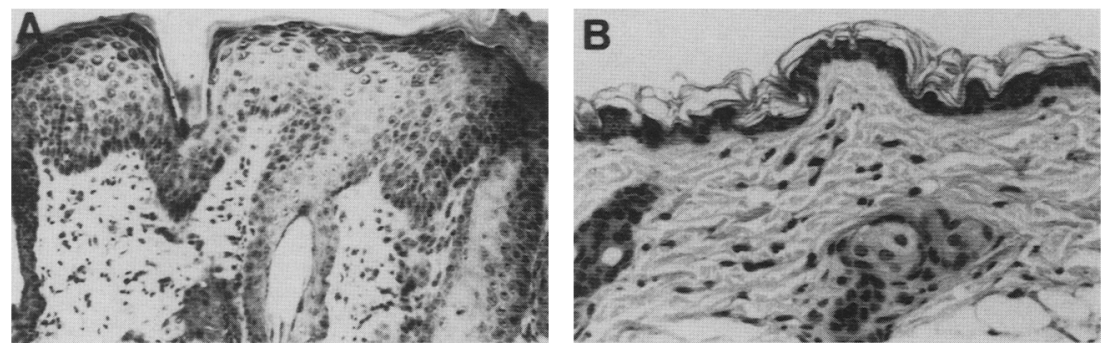

Figure 9. Effect of CD44 expression on the response to local carcinogen application. Skin section of control $(A)$ and transgenic $(B)$ mice 60 days following application of DMBA. Note the pronounced epidermal hyperplasia of control mice in contrast to the normal-appearing epidermis of transgenic animals. Original magnification, $40 x$.

but, rather, from a failure of keratinocytes to maintain it within the epidermis and to degrade the HA that they produce. The abnormal ultrastructural features of superficial dermal fibroblasts and their increased expression of CD44 may reflect activation by excess local HA and/or enhanced CD44-mediated HA internalization.

What is the role of HA maintained in the interkeratinocyte spaces through CD44 binding? Interactions between CD44 and HA may contribute to the regulation of the intercellular space, whose alteration in the transgenic mice may explain the change in morphology of basal keratinocytes. This view is supported by a recent study showing that CD44 participates in cell-cell interactions among keratinocytes (Hudson et al. 1995). Furthermore, the fact that HA attracts water molecules and helps create a hydrated, low-resistance matrix also suggests that maintenance of extracellular space in the epidermis may be one of its major functions, perhaps of particular importance in a stratified epithelium where the distance to the most superficial layers of the blood capillaries may be significant. The age-dependent augmentation of HA accumulation and associated histologic changes could be explained by a progressive increase in keratinocyte HA production or reduction in the effectiveness of CD44-independent mechanisms of HA elimination. Further work will be required to resolve this point.

The second major effect of CD44 expression loss by keratinocytes is a defect in their ability to proliferate in response to various stimuli in vivo and in vitro. The baseline proliferation appeared unaltered, as skin and corneal development were normal and resting state transgenic and normal keratinocytes displayed comparable proliferation rates in vitro. The reduced ability of cultured transgenic keratinocytes to proliferate in response to bFGF and HB-EGF is not unexpected, as both factors bind heparan sulfate side chains of CD44v3-containing isoforms (Bennett et al. 1995), which appear to constitute a major fraction of heparan sulfate proteoglycans expressed on the surface of normal keratinocytes (Hudson et al. 1995). Taken at face value, the inability of transgenic keratinocytes to proliferate in response to bFGF and HB-EGF would suggest that heparan sulfateassociated CD44 isoforms play a significant role in presenting these growth factors to their respective receptors in keratinocytes and may help explain the low keratinocyte proliferation rate in vivo following injury. Similarly, the impaired transgenic mouse keratinocyte proliferative response to exogenous HA may be explained by the inability of these cells to bind and internalize HA. Interaction between CD44 and ECM HA significantly enhances growth of various tumor types in vivo (Sy et al. 1991; Bartolazzi et al. 1994), and there is evidence that engagement of CD44 by HA may have a costimulatory effect on cytokine or growth factor-mediated cell activation and/or proliferation (Noble et al. 1993; Galandrini
A

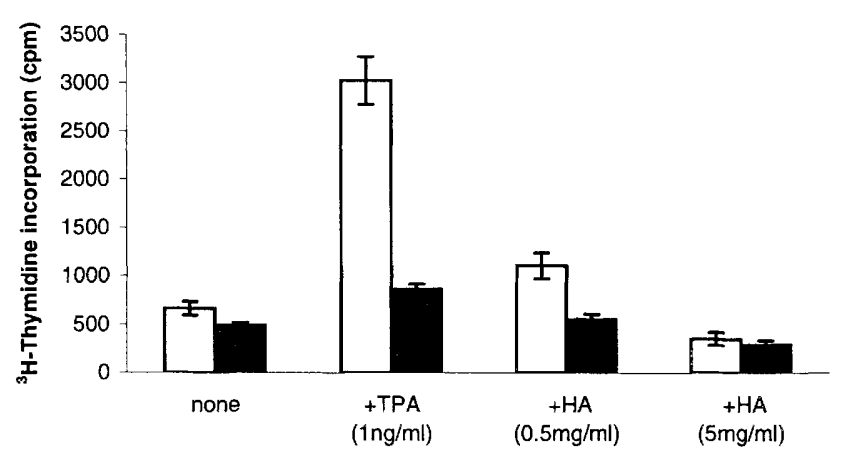

B

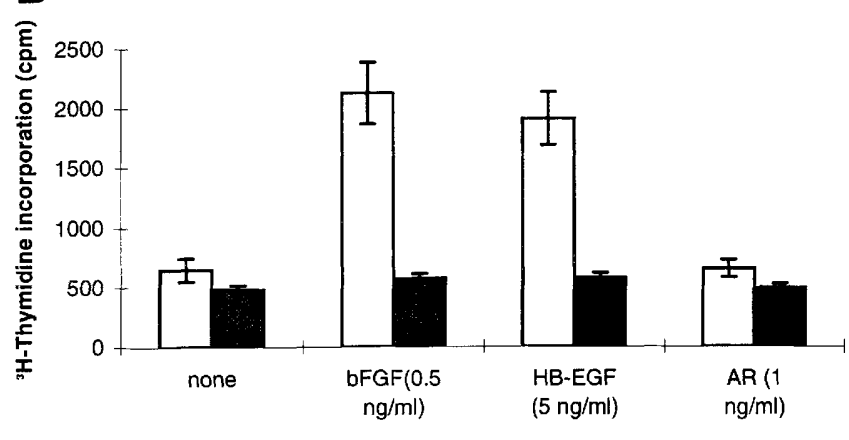

Figure 10. Keratinocyte proliferation in response to exogenous stimuli in vitro. Keratinocytes from normal and transgenic mice were grown on postmitotic fibroblast feeder layers at a ratio of 1:6 in 96-well plates. On day 12 of culture, TPA or HA $(A)$ and heparin-binding bFGF, HB-EGF, or AR $(B)$ were added to the wells at the indicated concentrations. Forty-eight hours later, $1 \mu \mathrm{Ci}$ of $\left[{ }^{3} \mathrm{H}\right]$ thymidine was added to each well and isotope incorporation evaluated $24 \mathrm{hr}$ later. All experiments were done in triplicate. 
et al. 1994). However, because expression of all keratinocyte CD44 isoforms is suppressed in our model and because both heparin-binding growth factors and hyaluronan are likely to stimulate keratinocyte proliferation in vivo, it is difficult at present to distinguish effects that result primarily from transgenic keratinocyte inability to bind bFGF and HB-EGF from those predominantly related to their inability to bind and internalize HA. Interestingly, loss of CD44 expression is also associated with keratinocyte inability to mount a proliferative response to phorbol ester both in vitro and in vivo, in stark contrast with the rapid epithelial thickening and keratinocyte CD44 overexpression following phorbol ester stimulation of the skin of normal animals. These observations suggest either that the CD44 polypeptide and/or its associated glycosaminoglycan side chains are implicated in the regulation of phorbol ester-triggered keratinocyte stimulation, a hitherto unrecognized role, or that CD44 may participate in more general signaling events required for the induction of keratinocyte proliferation by a broad range of extracellular stimuli.

All of the other consequences of the loss of CD44 expression in the epidermis that we observed in the transgenic mice, namely, decreased skin elasticity, delayed wound healing, impaired hair regrowth, and absence of epidermal hyperplasia in response to carcinogen, may be attributed to inappropriate HA accumulation, defective keratinocyte proliferation, or a combination of both. Accumulation of HA in the superficial dermis appeared to be the single most important factor in the observed loss of skin elasticity, as normal elasticity was temporarily restored following HA removal by local hyaluronidase injection. Delayed wound healing is most likely attributable to a combination of reduced skin elasticity (which increases the size of the wound), defective keratinocyte proliferation in response to external stimuli, and possibly impaired keratinocyte migration. CD44 is highly expressed in migrating keratinocytes at all stages of healing of human mucosal wounds (Oksala et al. 1995), and CD44 expression has been shown to promote cell migration directly on HA-coated substrates (Thomas et al. 1992). Ineffective interaction with HA because of CD44 loss can therefore be expected to at least partially inhibit HA-dependent keratinocyte migration through ECM. Delay in hair regrowth may be best explained by the observed defective proliferation in hair bulbs after hair pulling, as hair regrowth depends in part on the ability of follicular keratinocytes to proliferate. Importantly, absence of CD44 expression did not abrogate hair cycling, as all of the phases that constitute the normal hair cycle were visible in the transgenic animals. However, we cannot exclude the possibility that hair cycle duration may have been altered.

Finally, impaired solute uptake and/or diffusion because of subepidermal HA accumulation and associated epidermal structural changes, and not only the impaired ability of keratinocytes to proliferate, may also be an important factor in the lack of epidermal hyperplasia in response to carcinogen observed in the transgenic mice. It has been suggested that topical carcinogen induction of permanent hyperplasia and skin papillomas in mice requires mutations in bulge cells that are reached by the carcinogen only in the resting phase of hair growth (Andreasen and Engelbreth-Holm 1953; Borum 1954; Cotsarelis 1990). Impaired diffusion in transgenic mice could result in the reduced ability of carcinogen to reach the critical target cells.

Taken together, our observations provide strong support for the concept that keratinocyte CD44 regulates local HA metabolism and thereby participates in the control of intercellular communication and epidermal permeability. However, they also indicate that CD44 is implicated in the regulation of keratinocyte proliferation in response to a variety of extracellular stimuli. The transgenic animals presented here will provide a means to address the molecular mechanisms of CD44-mediated keratinocyte proliferation control.

\section{Materials and methods}

\section{Isolation of murine CD44 CDNA}

Full-length murine $\mathrm{CD} 44 \mathrm{H}$ (mCD44H) cDNA was amplified by PCR from MRL/lpr mouse lymph node-derived cDNA template using synthetic oligonucleotide primers containing HindIII and $X$ hoI restriction sites for the $5^{\prime}$ and $3^{\prime}$ ends of the coding region, respectively: forward primer, 5'-CGCGGGAAGCTTATGGACAAGTTTTGGTGGCACAC-AGCTTGG-3'; reverse primer, 5'-CGCGGGCTCGAGCTACAC-CCCAATCTTCATGTCCACA-CTCTG-3'. Thirty-five cycles of PCR amplification were performed, consisting of $1 \mathrm{~min}$ at $94^{\circ} \mathrm{C}, 2 \mathrm{~min}$ at $55^{\circ} \mathrm{C}$, and 3 min at $72^{\circ} \mathrm{C}$ in a $100-\mu l$ reaction mix containing $10 \mathrm{~mm}$ Tris$\mathrm{HCl}(\mathrm{pH} 8.3), 50 \mathrm{~mm} \mathrm{KCl}, 1.5 \mathrm{~mm} \mathrm{MgCl}_{2}, 200 \mu \mathrm{M}$ each dNTP, the appropriate primers at $750 \mathrm{nM}$, and 1 unit of Taq polymerase (Perkin Elmer Cetus, Emeryville, CA). Amplified mCD44H cDNA was subsequently inserted into the pBluescript (pBS) SK+ cloning vector using the restriction enzyme cleavage sites to yield the mCD44H-pBS vector. The cDNA was assessed for PCR-induced mutations by direct dideoxy sequencing.

Construction of the K5p-mCD44AS transgene and generation of transgenic mice

The 5.2-kb fragment of the bovine $\mathrm{K} 5$ gene 5 ' regulatory region (K5p) (Ramirez et al. 1994) was subcloned into pBS KS+ vector to yield the $\mathrm{K} 5 \mathrm{p}-\mathrm{pBS}$ plasmid. mCD44H cDNA was excised with HindIII-XhoI from mCD44H-pBS, blunted, and introduced in an antisense orientation into the blunted EcoRI site between the rabbit $\beta$-globin intron and polyadenylation sequences of $\beta$ glob-pBS to yield $\beta$ glob-mCD44AS. The $\beta$-globin intron, antisense $\mathrm{mCD} 44 \mathrm{H}$, and $\beta$-globin polyadenylation sequence were removed from $\beta$ glob-mCD44AS with SpeI-Xhol, blunted, and inserted into the SmaI site, downstream of $\mathrm{K} 5 \mathrm{p}$, in $\mathrm{K} 5 \mathrm{p}-\mathrm{pBS}$ to yield $\mathrm{K} 5 \mathrm{p}-\mathrm{mCD} 44 \mathrm{AS}$. Transgenic mice were generated as described previously (Hogan et al. 1986). The transgene construct was excised from the plasmid vector as a SalI-NotI fragment, purified by agarose gel electrophoresis and NACS columns (BRL Life Technologies, Inc., Gaithersburg, MD) and resuspended in microinjection buffer $(1 \mathrm{~mm}$ Tris-HcI at $\mathrm{pH} 7.4$ and $0.1 \mathrm{~mm}$ EDTA at $\mathrm{pH} 8.0$ ) to a final concentration of $5 \mathrm{ng} / \mathrm{\mu l}$. C57BL/ $6 \times \mathrm{DBA} / 2 \mathrm{~F}_{1}$ females were superovulated by sequential intraperitoneal injections of 5 units of pregnant mare serum (Sigma Chemical Co., St. Louis, MOl and $5 \mathrm{IU}$ of human chorionic gonadotropin (Sigma) and mated with fertile $\mathrm{F}_{1}$ males. Single- 
cell embryos were harvested the following day using M16 medium (Whittingham). Cumulus cells were removed by brief incubation in $1 \mathrm{mg} / \mathrm{ml}$ of bovine testicular hyaluronidase (Sigma). Pronuclei were microinjected with $\sim 1-2 \mathrm{pl}$ of the transgene construct DNA, and the injected embryos were reimplanted into pseudopregnant NMRI outbred female mice on the same day.

\section{DNA isolation and analysis}

Tail biopsy tissue was digested at $50^{\circ} \mathrm{C}$ for $4-6 \mathrm{hr}$ in $0.5 \mathrm{ml}$ of extraction buffer (10 mM Tris- $\mathrm{HCl}$ at $\mathrm{pH} 7.5,1 \mathrm{~mm}$ EDTA, $0.8 \times$ SSC, $1 \%$ SDS) containing $20 \mu \mathrm{g}$ of proteinase $\mathrm{K}$ and $10 \mu \mathrm{g}$ of $\mathrm{RNase}$. Restriction endonuclease digestion, agarose gel electrophoresis, and Southern blotting of purified DNA were performed according to standard procedures.

\section{Analysis of antisense RNA expression}

Total RNA preparation from the back skin of mice and reverse transcription were done as described above. Using oligonucleotides specific for the antisense CD44 cDNA strand and the poly (A) sequence, PCR was performed as described above except that the reaction mix was $20 \mu \mathrm{l}$ and 27 cycles were conducted. The following primers were used: ASForward, 5'. TATATACTCCTGTCTGGTTGGCTGCAC-3', and pTX, 5'CCCCTCGAGTTTTTTTTTTTTTTT-3'. Southern blotting on $10 \mu \mathrm{l}$ of each PCR product using $1.1 \mathrm{~kb}$ of entire $\mathrm{mCD} 44 \mathrm{H}$ cDNA was performed as described above.

\section{Production and purification of $\mathrm{mCD} 44 \mathrm{Rg}$ fusion protein}

The cDNA sequence encoding the extracellular portion of mCD44 was amplified by PCR as described above using mCD44H plasmid as a template and synthetic primers containing HindIII and $B g \Pi I$ restriction sites for the $5^{\prime}$ and $3^{\prime}$ extremities, respectively. After sequencing, the amplified cDNA segment was digested with the appropriate restriction enzymes and ligated to CDM8-immunoglobulin vector (Aruffo et al. 1990). The mCD44-immunoglobulin vector was introduced into COS cells by the DEAE-dextran method, and 5-7 days post-transfection, supernatants were harvested and soluble CD44Rg purified on protein A-trisacryl beads (Pierce Chemical Co., Rockford, IL) as described (Aruffo et al. 1990; Bartolazzi et al. 1994).

\section{Anti-CD44 and mCD44Rg staining of skin sections}

CD44 and HA detection was performed on cryostat sections of skin samples that were frozen in liquid nitrogen. Cryostat sections $(5 \mu \mathrm{m})$ were mounted onto slides, air-dried, preincubated with $10 \mu \mathrm{g} / \mathrm{ml}$ of goat IgG (Cappel, Malvern, PA) for $20 \mathrm{~min}$ at room temperature, and incubated with rat anti-mouse CD44 antibodies $(2.5 \mu \mathrm{g} / \mathrm{ml})$ or mCD44Rg purified protein $(-20 \mu \mathrm{g} /$ $\mathrm{ml}$ ) for $1 \mathrm{hr}$ at room temperature. Hyaluronidase treatment of tissues was performed by incubating frozen tissue sections with $1 \mu \mathrm{g} / \mathrm{ml}$ of bovine testicular hyaluronidase (Sigma) in PBS for 1 hr at $37^{\circ} \mathrm{C}$. After staining with the primary reagent, sections were washed three times with PBS, 5\% FCS, and $0.02 \% \mathrm{NaN}_{3}$; incubated with FITC-labeled affinity-purified goat anti-rat immunoglobulin or goat anti-human IgG (Cappel) antibodies for anti-CD44 and $\mathrm{mCD} 44 \mathrm{Rg}$, respectively, for $30 \mathrm{~min}$ at room temperature; washed; and examined under a Zeiss Axiophot microscope using appropriate filters.

\section{Histology and electron microscopy}

Skin samples were fixed in formaldehyde and embedded in paraffin. Sections were cut at 4-8 $\mu \mathrm{m}$, mounted onto slides, and stained with hematoxylin-eosin and van Gieson-elastin according to standard procedures. One-millimeter cubes from skin samples were fixed for $4 \mathrm{hr}$ at room temerature in $2 \%$ glutaraldehyde (Merck, Darmstadt, Germany) in $0.1 \mathrm{M} \mathrm{Na}$ cacodylate (Merck) buffer and stored in buffer overnight at $4^{\circ} \mathrm{C}$. The samples were postfixed in $2 \% \mathrm{OsO}_{4}$ (Merck), dehydrated in graded ethanols, and embedded in Epon 812 (Fluka Chemie AG, Bushs, Switzerland). Semithin sections were stained with methylene blue. Representative areas were selected for thin sections, collected on copper grids, double-stained with uranyl acetate and lead citrate (Merck), and examined with a Philips 400 electron microscope (Philips SA, Zurich, Switzerland).

\section{Keratinocyte isolation and culture}

Isolation of epidermal keratinocytes and establishment of human dermal fibroblast (HDF) feeder layers were carried out as described previously (Limat and Hunziker 1996; Limat et al. 1989). Briefly, $0.5 \mathrm{~cm}^{2}$ full-thickness back skin of mice was cut into four sections and treated with $1 \mathrm{U} / \mathrm{ml}$ of dispase (Boehringer Mannheim) in Dulbecco's modified Eagle medium (DMEM) supplemented with $10 \%$ FCS overnight at $4^{\circ} \mathrm{C}$. The epidermis was then detached from the dermis, rinsed with PBS, and incubated with $0.1 \%$ trypsin $(1: 250)$ and $0.02 \%$ EDTA in PBS without $\mathrm{Ca}^{2+}$ and $\mathrm{Mg}^{2+}(\mathrm{pH} 7.2)$ for $10 \mathrm{~min}$ at $37^{\circ} \mathrm{C}$. A suspension essentially consisting of single cells was obtained by pipetting the epidermis vigorously in DMEM supplemented with $10 \%$ DMEM. After centrifugation for $10 \mathrm{~min}$ at $200 \mathrm{~g}$, epidermal keratinocytes were resuspended in culture medium and seeded at a density of $0.5 \times 10^{3}$ to $1 \times 10^{3}$ cells $/ \mathrm{cm}^{2}$ on a HDF feeder layer. Primary cultures were performed in FED medium (a kind gift of Dr. A. Limat, University of Berne, Berne, Switzerland) composed of three parts DMEM and one part Ham's F12 supplemented with $10 \%$ FCS, insulin, hydrocortisone, adenine, triiodothyronine, choleratoxin, epidermal growth factor (EGF), penicillin, and streptomycin (Limat and Hunziker 1996).

Determination of keratinocyte HA binding and uptake and HA synthesis in vitro

Keratinocytes were cultured in six-well culture plates (Falcon, Becton Dickinson and Co., Franklin Lakes, NI as described above. HA-FL $(100 \mu \mathrm{g} / \mathrm{ml})$ or $\mathrm{mCD} 44 \mathrm{Rg}(100 \mu \mathrm{g} / \mathrm{ml})$ was added to the wells, and the cultures were maintained at $37^{\circ} \mathrm{C}$ for 1 or $24 \mathrm{hr}$. The cells were washed with PBS, fixed for $3 \mathrm{~min}$ in methanol at $-20^{\circ} \mathrm{C}$, mounted in polyvinylalcohol, and examined with a Zeiss LSM 410 confocal microscope /Carl Zeiss, Germany|. HA synthesis was determined according to methods described previously (Culty et al. 1992). Keratinocytes from transgenic and normal mice were incubated with fresh medium containing $20 \mu \mathrm{Ci} / \mathrm{ml}$ of $\left[{ }^{3} \mathrm{H}\right]$ glucosamine at $37^{\circ} \mathrm{C}$ for $24 \mathrm{hr}$. The culture media were collected and the cells were incubated with $0.05 \%$ trypsin, $0.02 \%$ EDTA (GIBCO), at $37^{\circ} \mathrm{C}$ for $30 \mathrm{~min}$ to release cell-surface HA. Trypsinized material was separated from the cells by centrifugation. Both medium and trypsinate were digested with $0.5 \%$ protease (type XIV, Sigma) overnight at $37^{\circ} \mathrm{C}$, boiled for $10 \mathrm{~min}$ to inactivate the protease, and centrifuged to separate denatured proteins from the supernatant. Carrier HA and chondroitin sulfate $(20 \mu \mathrm{g} / 0.6 \mathrm{ml})$ were added to the HA-containing supernatant, and the $\mathrm{HA}$ was precipitated with $10 \%$ cetylpyridinium chloride $(\mathrm{CPC})$ at $37^{\circ} \mathrm{C}$ for $1 \mathrm{hr}$. HA precipitates were centrifuged at $10,000 \mathrm{~g}$ for $10 \mathrm{~min}$, and the pellets 
were washed twice in $0.2 \% \mathrm{CPC}$ and dissolved in $0.5 \mathrm{ml}$ of methanol. Scintillation liquid was added to the methanol resolved solution and the radiolabel incorporation determined in a $\beta$ counter.

\section{Wound healing experiments}

Experimental wounds were created in the dorsal skin of control and transgenic mice. Mice were anesthetized with a single intraperitoneal injection of Avertin $[8 \mathrm{mg}$ in $0.3 \mathrm{ml}$ of $\mathrm{NaCl}(9$ grams/liter)]. A square-shaped full-thickness wound of 0.5 or 1 $\mathrm{cm}^{2}$ was made on the back by excising skin and panniculus carnosus. Animals with $0.5-\mathrm{cm}^{2}$ wounds were sacrificed or subjected to biopsy at day 5 after injury or after complete healing in control mice. The surface areas of $1-\mathrm{cm}^{2}$ wounds were measured by planimetry every 2 days after wounding until complete healing was obtained in the control mice. Incisions $10 \mathrm{~mm}$ long, 1 $\mathrm{mm}$ wide, and 1-2 mm deep/ were made on the back of mice, and biopsies were performed at day 1,3,5, and 7 after injury. Bovine testicular hyaluronidase $(100,000 \mathrm{U} / \mathrm{kg}$, Sigma $)$ or $\mathrm{NaCl}$ (9 grams/liter) control was injected intradermally $2 \mathrm{hr}$ before the incisions.

\section{In vivo and in vitro keratinocyte proliferation assays}

TPA $\left[200 \mu \mathrm{l}\right.$ of $10^{-4} \mathrm{M}$ solution in acetone as described by Akhurst et al. (1988)] was applied topically to each side of left ears of control and transgenic mice. Right ears were treated only with acetone. Two days after TPA application, a BrdU labeling experiment was performed. Interfollicular keratinocytes from control and transgenic mice were grown on postmitotic fibroblast feeder layers in 96-well plates at a ratio of 1:6. On day 12 of culture, TPA $(1 \mathrm{ng} / \mathrm{ml}), \mathrm{HA}(0.5$ and $5 \mathrm{mg} / \mathrm{ml})$, human $\mathrm{bFGF}$ $(0.5 \mathrm{ng} / \mathrm{ml}$, R\&D Systems Inc., Minneapolis, $\mathrm{MN} \mid$, human heparin-binding EGF (HB-EGF, $5 \mathrm{ng} / \mathrm{ml}$, R\&D Systems), or human amphiregulin (AR, $1 \mathrm{ng} / \mathrm{ml}, \mathrm{R} \& \mathrm{D}$ Systems) was added to the cultures. Forty-eight hours later $1 \mu \mathrm{Ci}$ of $\left[{ }^{3} \mathrm{H}\right]$ thymidine (Amersham) was added to each well. Isotope incorporation was evaluated $24 \mathrm{hr}$ later in a Beckman LS $1801 \beta$ counter (Beckman, Irvine, CA). All experiments were done in triplicate, and the results were expressed as the mean of incorporated counts per minute for each condition tested.

\section{Analysis of hair regrowth and hair cycle}

Five 12-day-old and ten 24-day-old mice were subjected to skin biopsy and histologic examination. Hairs of the control and transgenic mice, which were in the resting phase after the second hair cycle (between 30 and 65 days old) were plucked to form a $0.5-\mathrm{cm}^{2}$ hairless area on the back skin. After 10 days when the first hair regrowth occurred, the same procedure was repeated and the second regrowth was analyzed.

\section{BrdU labeling}

On day 2 after TPA application and after hair plucking, on day 3 after incision, or on day 5 after $0.5-\mathrm{cm}^{2}$ wound injuries, mice were injected intraperitoneally with BrdU /Sigma; $250 \mathrm{mg} / \mathrm{kg}$ of body weight) and subjected to ear or back skin biopsies $2 \mathrm{hr}$ after injection. Detection of BrdU on 4- $\mu \mathrm{m}$ paraffin sections with anti-BrdU antibodies was performed by using the BrdU Labeling and Detection Kit I of Boehringer Mannheim Biochemical GMBH (Mannheim, Germany). BrdU-positive and -negative cells were scored per microscopic field, and the percentage of cells incorporating BrdU was calculated. Five microscopic fields were examined per mouse, and a total of five mice were used in each experiment.

\section{Carcinogen application}

Fifty microliters of a $0.5 \%$ solution of 7,12-dimethylbenz $[a]-$ anthracene (DMBA, Aldrich Chemical Co., Milwaukee, WI) in benzene (Merck) was applied to shaved dorsal skin of control and transgenic mice. Mice were examined two to three times weekly, and the carcinogen-treated skin regions were subjected to biopsy 60 days following treatment.

\section{Acknowledgments}

We thank Drs. P. Meda, D. Salomon, and A. Limat for fruitful discussions, Ms. J. Stalder for excellent technical help, Ms. J. $\mathrm{Ntah}$ for secretarial work, and Mr. J.-C. Rumbeli and Mr. E. Denkinger for photography. This work was supported in part by U.S. Public Health Services grant CA55735 to I.S. I.S. is a Scholar of the Leukemia Society of America.

The publication costs of this article were defrayed in part by payment of page charges. This article must therefore be hereby marked "advertisement" in accordance with 18 USC section 1734 solely to indicate this fact.

\section{References}

Akhurst, R.J, F. Fee, and A. Balmain. 1988. Localized production of TGF- $\beta$ mRNA in tumor promoter-stimulated mouse epidermis. Nature 331: 363-365.

Andreasen, E. 1953. Cyclic changes in the skin of the mouse. Acta Path. Microbiol. Scand. Sect. A. Pathol. 32: 157-164.

Andreasen, E. and K. Borum. 1958. Histology of early reactions following a single application of 9,10-dimethyl-1,2-benzanthracene to mouse skin in two different stages of hair formation. Acta Pathol. Microbiol. Scand. Sect. A. Pathol. 38: $59-71$.

Andreasen, E. and J. Engelbreth-Holm. 1953. On the significance of the mouse hair cycle in experimental carcinogenesis. Acta Pathol. Microbiol. Scand. Sect. A. Pathol. 32: 165169.

Aruffo, A., I. Stamenkovic, M. Melnick, C.B. Underhill, and B. Seed. 1990. CD44 is the principal cell surface receptor for hyaluronate. Cell 61: 1303-1313.

Bartolazzi, A., R. Peach, A. Aruffo, and I. Stamenkovic. 1994. Interaction between CD44 and hyaluronate is directly implicated in the regulation of tumor development. /. Exp. Med. 180: 53-66.

Bennett, K.L., D.G. Jackson, J.C. Simon, E. Tanczos, R. Peach, B. Modrell, I. Stamenkovic, G. Plowman, and A. Aruffo. 1995. CD44 isoforms containing exon V3 are responsible for the presentation of heparin-binding growth factor. I. Cell Biol. 128: 687-698.

Bertolami, C.N., S. Berg, and D.V. Messadi. 1992. Binding and internalization of hyaluronate by human cutaneous fibroblasts. Matrix 12: 11-21.

Borum, K. 1954. The role of the mouse hair cycle in epidermal carcinogenesis. Acta Pathol. Microbiol. Scand. Sect. A. Pathol. 34: 542-553.

Byme, C. and E. Fuchs. 1993. Probing keratinocyte and differentiation specificity of the human K5 promoter in vitro and in transgenic mice. Mol. Cell. Biol. 13: 3176-3190.

Cotsarelis, G., T.T. Sun, and R.M. Lavker. 1990. Label-retaining cells reside in the bulge area of pilosebaceous unit: implica- 
tions for follicular stem cells, hair cycle, and skin carcinogenesis. Cell 61: 1329-1337.

Culty, M., H.A. Nguyen, and C.B. Underhill. 1992. The hyaluronan receptor (CD44) participates in the uptake and degradation of hyaluronan. I. Cell Biol. 116: 1055-1062.

Fenderson, B.A., I. Stamenkovic, and A. Aruffo. 1993. Localization of hyaluronan in mouse embryos during implantation, gastrulation and organogenesis. Differentiation 54: 85-98.

Fraser, J.R.E. and T.C. Laurent. 1989. Turnover and metabolism of hyaluronan. The biology of hyaluronan. CIBA Found. Symp. 143: 41-59.

Galandrini, R., E. Galluzzo, N. Albi, C.E. Grossi, and A. Velardi. 1994. Hyaluronate is costimulatory for human T cell effector functions and binds to CD44 on activated T cells. J. Immunol. 153: 21-31.

Gunthert, U., M. Hofmann, W. Rudy, S. Reber, M. Zoller, I. Haussmann, S. Matzku, A. Wenzel, H. Ponta, and P. Herrlich. 1991. A new variant of glycoprotein CD44 confers metastatic potential to rat carcinoma cells. Cell 65: 13-24.

Hogan, B., F. Constantini, and E. Lacy, ed. 1986. Manipulating the mouse embryo: A laboratory manual Cold Spring Harbor Labortory Press, Cold Spring Harbor, NY.

Hudson, D.L., J. Sleeman, and F.M. Watt. 1995. CD44 is the major peanut lectin-binding glycoprotein of human epidermal keratinocytes and plays a role in intercellular adhesion. J. Cell Sci. 108: 1959-1970.

Jalkanen, S. and M. Jalkanen. 1992. Lymphocyte CD44 binds the $\mathrm{COOH}$ terminal heparin-binding domain of fibronectin. I. Cell Biol. 116: 817-825.

Jalkanen, S.T., R.F. Bargatze, L.R. Herron, and E.C. Butcher. 1986. A lymphoid cell surface glycoprotein involved in endothelial cell recognition and lymphocyte homing in man. Eur. J. Immunol. 16: 1195-1202.

Katsuki, M., M. Sato, M. Kimura, M. Yokoyama, K. Kobayashi, and T. Nomura. 1988. Conversion of normal behavior to shiverer by myelin basic protein antisense cDNA in transgenic mice. Science 241: 593-595.

Laurent, T.C. and J.R. Fraser. 1992. Hyaluronan. FASEB J. 6: 2397-2404.

Lesley, J., R. Hyman, and P.W. Kincade. 1993. CD44 and its interaction with extracellular matrix. $A d v$. Immunol. 54: 271-335.

Limat, A. and T. Hunziker. 1996. Cultivation of keratinocytes from the outer root sheath of human hair follicles. Human cell culture protocols. Methods Mol. Biol. 20: 1-11.

Limat, A., T. Hunziker, C. Boillat, K. Bayreuther, and F. Noser. 1989. Post-mitotic human dermal fibroblasts efficiently support the growth of human follicular keratinocytes. I. Invest. Dermatol. 92: 758-762.

Miyake, K., K.L. Medina, S. Hayashi, S. Ono, T. Hamaoka, and P.W. Kincade. 1990a. Monoclonal antibodies to Pgp-1/CD44 block lympho-hemopoiesis in long-term bone marrow cultures. I. Exp. Med. 171: 477-488.

Miyake, K., C.B. Underhill, J. Lesley and P.W. Kincade. 1990b. Hyaluronate can function as a cell adhesion molecule and CD44 participates in hyaluronate recognition. I. Exp. Med. 172: 69-75.

Naujokas, M.F., M. Morin, M.S. Anderson, M. Peterson, and J. Miller. 1993. The chondroitin sulfate form of invariant chain can enhance stimulation of $\mathrm{T}$ cell responses through interaction with CD44. Cell 74: 257-268.

Noble, P.W., F.R. Lake, P.M. Henson, and D.W.H. Riches. 1993. Hyaluronate activation of CD44 induces insulin-like growth factor- 1 expression by a tumor necrosis factor- $\alpha$-dependent mechanism in murine macrophages. J. Clin Invest. 91: 2368-2377.
Oksala, O., T. Salo, R. Tammi, L. Hakkinen, M. Jalkanen, P. Inki, and H. Larjava. 1995. Expression of proteoglycans and hyaluronan during wound healing. J. Histochem. Cytochem. 43: $125-135$.

Pepin, M.-C., F. Pothier, and N. Barden. 1992. Impaired type II glucocorticoid-receptor function in mice bearing antisense RNA transgene. Nature 355: 725-728.

Ramirez, A., A. Bravo, J.L. Jorcano, and M. Vidal. 1994. Sequences $5^{\prime}$ of the bovine keratin 5 gene direct tissue- and cell-type-specific expression of a lacZ gene in the adult and during development. Differentiation 58: 53-64.

Screaton, G.R., M.V. Bell, D.G. Jackson, F.B. Cornelis, U. Gerth, and J.I. Bell. 1992. Genomic structure of DNA encoding the lymphocyte homing receptor CD44 reveals at least 12 alternatively spliced exons. Proc. Natl. Acad. Sci. 89: 1216012164.

Shimizu, Y., G.A. van Seventer, R. Siraganian, L. Wahl, and S. Shaw. 1989. Dual role of the CD44 molecule in T cell adhesion and activation. J. Immunol. 143: 2457-2463.

Stamenkovic I., A. Aruffo, M. Amiot, and B. Seed. 1991. The hematopoietic and epithelial forms of CD44 are distinct polypeptides with different adhesion potentials for hyaluronate-bearing cells. EMBO T. 10: 343-348.

Sy, M.S., Y.J. Guo, and I. Stamenkovic. 1991. Distinct effects of two CD44 isoforms on tumor growth in vivo. I. Exp. Med. 174: 859-866.

Tammi, R., J. Ripellino, R.U. Margolis, and M. Tammi. 1988. Localization of epidermal hyaluronic acid using the hyaluronate binding region of cartilage proteoglycan as a specific probe. J. Invest. Dermatol. 90: 412-413.

Tammi, R., A.M. Saamanen, H.I. Maibach, and M. Tammi. 1991. Degradation of newly synthesized high molecular mass hyaluronan in the epidermal and dermal compartments of human skin in organ culture. I. Invest. Dermatol. 97: 126-130.

Thomas, L., H.R. Byers, J. Vink, and I. Stamenkovic. 1992. $\mathrm{CD} 44 \mathrm{H}$ regulates tumor cell migration on hyaluronatecoated substrate. J. Cell Biol. 118: 971-977.

Toole, B.P. 1982. Glycosaminoglycans and morphogenesis. In Cell biology of the extracellular matrix (ed. E.D. Hay), pp. 259-294. Plenum Publishing, New York, NY.

- 1990. Hyaluronan and its binding proteins, the hyaladherins. Curr. Opin. Cell Biol, 2: 839-844.

Wang, C., M. Tammi, and R. Tammi. 1992. Distribution of hyaluronan and its CD 44 receptor in the epithelia of human skin appendages. Histochemistry 98: 105-112.

Weber, G.F., S. Ashkar, M.J. Glimcher, and H. Cantor. 1996. Receptor-ligand interaction between CD44 and osteopontin (Eta-1). Science 271: 509-512. 


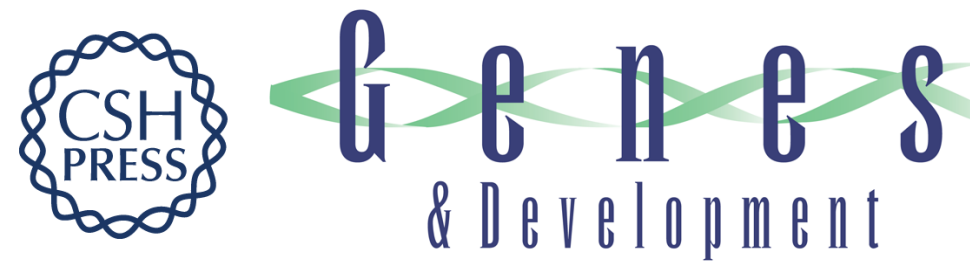

\section{Selective suppression of CD44 in keratinocytes of mice bearing an antisense CD44 transgene driven by a tissue-specific promoter disrupts hyaluronate metabolism in the skin and impairs keratinocyte proliferation.}

G Kaya, I Rodriguez, J L Jorcano, et al.

Genes Dev. 1997, 11:

Access the most recent version at doi:10.1101/gad.11.8.996

References This article cites 41 articles, 14 of which can be accessed free at: http://genesdev.cshlp.org/content/11/8/996.full.html\#ref-list-1

License

Email Alerting Service

Receive free email alerts when new articles cite this article - sign up in the box at the top right corner of the article or click here.

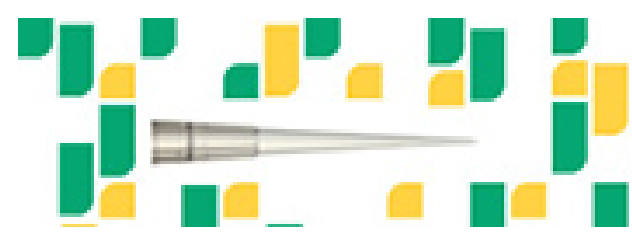

Focused on your science. 